\title{
Radiographic study of the proximal femur morphology of elderly patients with femoral neck fractures: is there a difference among ethnic groups?
}

\author{
Zhi Hao $\underline{T a n g}^{1}$, MBBS, MRCS, Ching Sing Nicholas $\underline{Y e o h}^{1}$, MBBS, MRCS, Gek Meng Jeffrey $\underline{\operatorname{Tan}}^{1}$, MBBS, FRCS
}

INTRODUCTION This study aimed to determine ethnic differences in the proximal femur morphology of elderly patients with femoral neck fractures in Singapore.

METHODS We reviewed the medical records of 101 men and 288 women aged 60-109 (mean 76.4) years who underwent hip hemiarthroplasty for femoral neck fractures between 1 June 2010 and 31 December 2015. Patients' age, gender and race were recorded. Plain anteroposterior radiography was used to measure the following: calcar width to canal width ratio of the ipsilateral femur; neck-shaft angle; hip offset; neck length; and neck width of the contralateral proximal femur. RESULTS Chinese women had slightly larger femoral heads (mean $43.88 \mathrm{~mm}$ ) as compared to Malay (mean $42.92 \mathrm{~mm}$, $\mathrm{p}=0.044$ ) and Indian (mean $42.34 \mathrm{~mm}, \mathrm{p}=0.025$ ) women. Chinese women also had a significantly lower mean calcarto-canal width ratio $(0.606)$ as compared to Malay $(0.664, p=0.002)$ and Indian $(0.693, p=0.004)$ women. The mean neck-shaft angle of Chinese women was significantly greater than that of Indian women ( $137.48^{\circ} \mathrm{vs} .127 .00^{\circ}, p=0.001$ ). CONCLUSION We found statistically significant differences in the femoral head sizes and calcar-to-canal width ratios among women of different ethnic groups. There were also differences in neck-shaft angles between Chinese and Indian women, and between Malay and Indian women.

Keywords: Dorr classification, femur head size, morphology, proximal femur, Singapore population

\section{INTRODUCTION}

Hip fractures are increasingly common worldwide ${ }^{(1)}$ and can result in mortality rates of more than $20 \% .^{(2,3)}$ A ten-year study on hip fractures in a Singapore hospital showed that $68.8 \%$ of femoral neck fractures were treated with hemiarthroplasty. ${ }^{(4)}$ Umer et al found that the proximal femur morphology of the general healthy population (age 20-50 years) in Pakistan differed significantly from those in Western countries. ${ }^{(5)}$ Lee et al found that among the Chinese, Malay and Indian races in Malaysia, the Chinese had significantly larger femoral head sizes compared to the other races; ${ }^{\left({ }^{(6)}\right.}$ however, the authors did not study other parameters of the proximal femur besides the femoral head sizes. Chin et al described Asian women as having smaller distal femurs. ${ }^{(7)}$ We hypothesised that there are differences among the ethnic groups in the proximal femur morphology of elderly patients with femoral neck fractures in the Singapore population.

\section{METHODS}

This retrospective cross-sectional study reviewed all patients who underwent hip hemiarthroplasty for femoral neck fractures between 1 June 2010 and 31 December 2015 at the Department of Orthopaedic Surgery, Khoo Teck Puat Hospital, Singapore. The following patient data was collected from electronic records and digital radiographs: age; gender; race; bone mineral density (BMD) of the hip; and body mass index (BMI). The calcar-to-canal width ratio (CC ratio) of all ipsilateral femurs was measured on digital anteroposterior (AP) plain radiographs of the hip. The neck-shaft angle, hip offset, neck length and neck width of the contralateral proximal femurs were measured on digital AP plain radiographs of the pelvis. The measurements were performed by a senior orthopaedic resident. Exclusion criteria were: age $<60$ years, previous surgery or existing deformity of the contralateral hip, deformed femoral head secondary to avascular necrosis and advanced arthritis.

Proximal femur morphology was analysed using the canal-tocalcar isthmus ratio, as described by Dorr et al. ${ }^{\left({ }^{(8)}\right.}$ Measurements were made based on AP radiographs of the hip contralateral to the femur neck fracture. A horizontal reference line was drawn from the apex of the lesser trochanter. Two points on the endosteal margins of the femur $(3 \mathrm{~cm}$ and $10 \mathrm{~cm}$ below the reference line) were identified. Lines joining the distal and proximal endosteal points were drawn on the lateral and medial sides. The two longitudinal lines intercepted the mid-lesser trochanteric line at two points; the distance between these two points was the proximal calcar isthmus diameter. The horizontal distance between the two endosteal margins, at $10 \mathrm{~cm}$ below the reference line, was the canal diameter. The $\mathrm{CC}$ ratio was obtained by dividing the canal diameter by the calcar diameter. The method of measurement is shown in Fig. 1.

The neck-shaft angle was measured between the long axis of the femoral neck and the longitudinal intramedullary axis of the femur. The hip offset was taken as the perpendicular distance

${ }^{1}$ Department of Orthopaedic Surgery, Khoo Teck Puat Hospital, Singapore

Correspondence: Dr Tang Zhi Hao, Senior Resident, Department of Orthopaedic Surgery, Khoo Teck Puat Hospital, 90 Yishun Central, Singapore 768828. ZhiHao.Tang@mohh.com.sg 


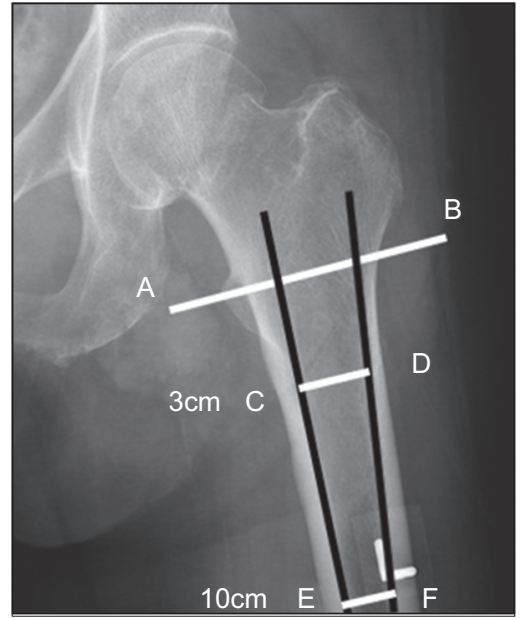

Fig. 1 Anteroposterior radiograph of the hip shows the measurement method. The calcar-to-canal width ratio is obtained by dividing the canal diameter (line EF) by the calcar diameter (line CD). These two diameters are $3 \mathrm{~cm}$ and $10 \mathrm{~cm}$, respectively, below reference line $A B$, which goes across the apex of the lesser trochanter. The two black lines join $\mathrm{C}$ and $\mathrm{E}$ as well as $\mathrm{D}$ and $\mathrm{F}$ along the endosteal margins.

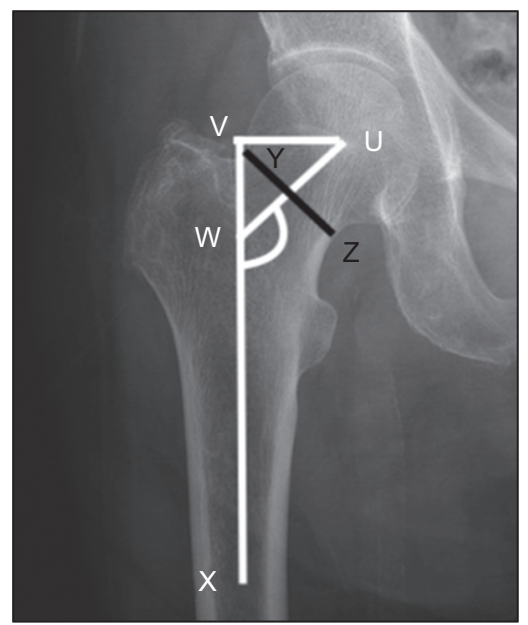

Fig. 2 Anteroposterior radiograph of the pelvis shows the neck offset (line UV), neck width (line YZ) and neck length (line YZ). The neck-shaft angle is the angle subtended by UWX.

from the intramedullary axis of the femur to the centre of the femoral head. Neck length was measured from the centre of the head along the intramedullary axis of the neck to where it meets the intramedullary axis of the femoral shaft. The width of the neck was taken as the shortest distance between the endosteal surfaces of the femoral neck, perpendicular to the intramedullary axis of the femoral neck. The method of measurement is shown in Fig. 2.

The sizes of the femoral heads removed during hemiarthroplasty were obtained from the patients' surgical records. The femoral heads were measured by the surgeons intraoperatively using a caliper, a commonly practised technique that usually provides an accurate measurement of the femoral head. Since direct measurements of the femoral heads were available, we chose to use these instead of measurements of the radiographs. Data was compared and analysed with ANOVA and Pearson correlation using IBM SPSS Statistics version 22.0 (IBM Corp, Armonk, NY, USA). Statistical significance was set at $p<0.05$.

\section{RESULTS}

During the study period, a total of 425 hip hemiarthroplasties were performed for patients with femoral neck fractures. Of these patients, 24 were excluded due to previous contralateral hip fractures, and 12 were excluded as the patients were below the age of 60 years. A total of 389 patients were included - 288 (74.0\%) female and 101 (26.0\%) male. There were 221 left and 168 right hip hemiarthroplasties. The mean age of the patients was 76.4 (range 60-109) years. Of the 389 patients, 324 (83.3\%) were Chinese, $45(11.6 \%)$ Malay, $14(3.6 \%)$ Indian and $6(1.5 \%)$ of other races. In 2014 , the Singapore population was made up of $74.3 \%$ Chinese, $13.3 \%$ Malay, $9.3 \%$ Indian and $3.3 \%$ other races ${ }^{(9)}$ which is similar to the ethnic composition of the present study.

Overall, there were no differences in age and $\mathrm{BMI}$ among the ethnic groups. BMD was measured for 235 of the patients. Our results showed that the $\mathrm{CC}$ ratio had no correlation with $\mathrm{BMD}$ of the hip $(r=-0.203)$. The BMI results of 350 patients were available, but they were not documented in the records of the remaining 39 patients. There was no correlation between the CC ratio and $\mathrm{BMI}(\mathrm{r}=-0.28)$.

Of the 288 female patients, 235 were Chinese, 36 Malay, 13 Indian and four of other races. Among the various subgroups within the female patient population, there were no significant differences in age and BMI. Chinese women had slightly larger femoral heads (43.88 mm) compared to Malay $(42.92 \mathrm{~mm}$, $\mathrm{p}=0.044)$ and Indian (42.34 mm, p = 0.025) women. Chinese women also had a significantly lower CC ratio (0.606) compared to Malay $(0.664, \mathrm{p}=0.002)$ and Indian $(0.693, \mathrm{p}=0.004)$ women. The neck-shaft angle of Chinese women was significantly greater than that of Indian women $\left(137.48^{\circ}\right.$ vs. $\left.127.00^{\circ}, p=0.001\right)$. There was also a significant difference between the neck-shaft angles of Malay and Indian women (138.20 vs. $127.00^{\circ}, \mathrm{p}=$ $0.001)$. There were no significant differences in head offset, neck width and neck length among women from different races. The differences between the women of different ethnic groups are summarised in Tables I and II.

Out of the 101 male patients, 89 were Chinese, nine Malay, one Indian and two of other races. As there was only one Indian man and two men from other races, we could not perform a meaningful comparison. The mean femoral head size of Chinese men was $49.23 \mathrm{~mm}$, while that of Malay men was $48.63 \mathrm{~mm}$; no statistical significance was found $(p=0.824)$. Although there was a slight difference between the $\mathrm{CC}$ ratios of Chinese and Malay men (0.595 vs. 0.627), it was not statistically significant $(p=0.732)$. Similarly, no statistically significant differences were found between Chinese and Malay men in terms of head offset, neck width, neck length and neck-shaft angles. The results are summarised in Table III.

\section{DISCUSSION}

Dorr et al described three main types of proximal femoral morphology ${ }^{(8)}$ Type A has thicker cortices, a good structural funnel shape and a narrow lateral diaphyseal canal isthmus that permits good fixation. Type B has thinner cortices and a relatively higher intramedullary canal diameter that allows 
Table I. Measurements of female patients $(n=288)$.

\begin{tabular}{|c|c|c|c|c|c|c|c|}
\hline \multirow[t]{2}{*}{ Ethnicity } & \multirow{2}{*}{$\begin{array}{c}\text { No. of } \\
\text { patients }\end{array}$} & \multicolumn{6}{|c|}{ Mean } \\
\hline & & CC ratio & Head size $(\mathrm{mm})$ & Head offset (mm) & Neck width (mm) & Neck length (mm) & $\begin{array}{c}\text { Neck-shaft } \\
\text { angle }\left(^{\circ}\right)\end{array}$ \\
\hline Malay & 36 & 0.664 & 42.92 & 31.82 & 33.46 & 47.04 & 138.20 \\
\hline Indian & 13 & 0.693 & 42.34 & 37.79 & 32.16 & 51.18 & 127.00 \\
\hline Others & 4 & 0.615 & 45.00 & 30.21 & 33.77 & 41.26 & 136.38 \\
\hline
\end{tabular}

Differences between head offset, neck width and neck lengths did not reach statistical significance (i.e. $p \geq 0.05$ ). CC ratio: calcar-to-canal width ratio

Table II. Comparison of calcar-to-canal width ratio (CC ratio), femoral head sizes and neck-shaft angles among female patients.

\begin{tabular}{|c|c|c|c|c|}
\hline \multirow[t]{2}{*}{ Ethnicity } & \multicolumn{4}{|c|}{ p-value } \\
\hline & Chinese & Malay & Indian & Others \\
\hline \multicolumn{5}{|l|}{ CC ratio } \\
\hline Chinese & - & $0.002^{*}$ & $0.004^{*}$ & 0.998 \\
\hline Malay & - & - & 0.753 & 0.720 \\
\hline Indian & - & - & - & 0.421 \\
\hline Others & - & - & - & - \\
\hline \multicolumn{5}{|c|}{ Femoral head size } \\
\hline Chinese & - & $0.044^{*}$ & $0.025^{*}$ & 0.696 \\
\hline Malay & - & - & 0.726 & 0.214 \\
\hline Indian & - & - & - & 0.084 \\
\hline Others & - & - & - & - \\
\hline \multicolumn{5}{|c|}{ Neck-shaft angle } \\
\hline Chinese & - & 0.968 & $0.001^{*}$ & 0.995 \\
\hline Malay & - & - & $0.001^{*}$ & 0.979 \\
\hline Indian & - & - & - & 0.247 \\
\hline Others & - & - & - & - \\
\hline
\end{tabular}

${ }^{*} p<0.05$ was statistically significant.

for implant fixation. Type $\mathrm{C}$ has the thinnest cortices and the widest intramedullary canal of the three, resulting in a stovepipe appearance, and is considered a poor candidate for cementless femur stems; this led some surgeons to use cemented stems in this type of femur. A mismatch between tapered cementless stems and proximal femur canals may give inferior results.

Care should also be taken when treating patients with stovepipe and champagne-flute morphology. Cooper et al's study ${ }^{(10)}$ showed that when the stem size increases, the smooth distal portion of a proximally coated stem increases relatively more than the proximal coated portion. This causes a greater degree of canal fill, resulting in distal rather than proximal wedging and fixation, which then leads to an increased risk of failed osteointegration. ${ }^{(10)}$ Ishii et al opined that in Asians, this was due to a smaller femoral canal size, causing distal fixation in champagne-flute morphology femurs. ${ }^{(11)}$

In octogenarians, canal flaring changes asymmetrically, with increased medial flaring and less lateral flaring. ${ }^{(12)}$ Our results showed that there was no correlation between BMD of the hip and CC ratio. Similarly, Yeung et al ${ }^{(13)}$ found no correlation between $\mathrm{CC}$ ratio and the presence of osteoporosis. In osteoporosis, there is typically widening of the endosteal diameter and thinning of the cortices. BMD loss was reported to show significant correlation with expansion of the medullary canal. ${ }^{(14)}$ We hypothesised that the $\mathrm{CC}$ ratio may not vary considerably between non-osteoporotic and osteoporotic bone, as it is the ratio of two endosteal diameters.

In the present study, Chinese women had significantly larger femoral heads than Malay and Indian women. This finding was consistent with that of a Malaysian study comprising the same racial groups. ${ }^{(6)}$ During a hip hemiarthroplasty procedure, the femoral head is replaced with a shell that is of the exact size as the native femoral head (measured intraoperatively with a caliper). Thus, knowledge of the mean femoral head diameter size provides the surgeon with a guide to the optimal size of the shell that should be used to replace the femoral head. This is of clinical importance, because if a femoral prosthetic head being used to replace the native femoral head is too small, it can increase the risk of prosthetic joint dislocation postoperatively. Our results also showed that Chinese women had a significantly smaller CC ratio compared to other races; to the best of our knowledge, this has neither been studied nor reported in the literature. Although Chinese men had slightly smaller mean CC ratios and slightly larger femoral head sizes than Malay men, the differences were not statistically significant.

Knowledge of proximal femur morphology is essential in deciding the use of femur stems in hip hemiarthroplasty. The smaller the $\mathrm{CC}$ ratio is, the more the femur resembles a stovepipe appearance. More accommodating designs that will enable proximal and distal fitting of femur components at the femoral canal are needed, so that stable fixation can be achieved. ${ }^{(15)}$ Patients with Dorr Type $\mathrm{C}$ femurs have traditionally been considered poor candidates for the use of cementless stems due to the combination of bone shape and poorer local biologic environment. Hence, surgeons may be more inclined to use a cemented stem instead of a tapered cementless stem for such patients. Awareness of the differences in femoral head size and $\mathrm{CC}$ ratio among the races would allow the surgeon to make a more informed decision regarding the choice of femur stem.

One of the limitations of the present study is the small number of Malay and Indian patients, although this is to be expected as there is a lower proportion of Malays and Indians in the Singapore population. The disproportionately high ratio of Chinese men in the study precludes any meaningful comparison. The lower proportion of men in the study was also expected, as osteoporotic femur neck fractures are known to occur more frequently in women. A larger study is required to determine if significant differences exist among men from different ethnic groups.

We acknowledge that a single-person measure and the lack of analysis for inter- and intra-observer differences are 
Table III. Measurements of male patients $(n=101)$.

\begin{tabular}{|c|c|c|c|c|c|c|c|}
\hline \multirow[t]{2}{*}{ Ethnicity } & \multirow{2}{*}{$\begin{array}{c}\text { No. of } \\
\text { patients }\end{array}$} & \multicolumn{6}{|c|}{ Mean \pm standard deviation } \\
\hline & & CC ratio & $\begin{array}{c}\text { Head } \\
\text { size }(\mathrm{mm})\end{array}$ & $\begin{array}{c}\text { Head } \\
\text { offset }(\mathbf{m m})\end{array}$ & $\begin{array}{c}\text { Neck } \\
\text { width }(\mathrm{mm})\end{array}$ & $\begin{array}{c}\text { Neck } \\
\text { length }(\mathrm{mm})\end{array}$ & $\begin{array}{l}\text { Neck-shaft } \\
\text { angle }\left({ }^{\circ}\right)\end{array}$ \\
\hline Chinese & 89 & $0.595 \pm 0.114$ & $49.23 \pm 2.81$ & $36.34 \pm 9.04$ & $39.73 \pm 3.88$ & $53.18 \pm 8.35$ & $138.48 \pm 8.24$ \\
\hline Malay & 9 & $0.627 \pm 0.092$ & $48.63 \pm 2.39$ & $36.82 \pm 10.82$ & $39.26 \pm 3.11$ & $53.88 \pm 7.34$ & $136.90 \pm 11.00$ \\
\hline Indian & 1 & 0.712 & 48.00 & 27.39 & 41.57 & 46.97 & 148.1 \\
\hline Others & 2 & $0.524 \pm 0.110$ & $47.00 \pm 0.00$ & $33.68 \pm 1.94$ & $36.10 \pm 1.92$ & $50.26 \pm 1.90$ & $137.2 \pm 4.24$ \\
\hline
\end{tabular}

Differences between head offset, neck width and neck lengths did not reach statistical significance ( $\mathrm{p} \geq 0.05)$. Mean calcar-to-canal width ratio (CC ratio) and head size differences between Chinese and Malays were not statistically significant at $p=0.732$ and $p=0.824$, respectively.

other limitations of the study. In addition, the rotation of the radiographs or the positions of the femur may have affected the measurement results. As our institution has a standard protocol for taking radiographs of the pelvis for hip fracture cases (the radiograph machine has an inbuilt retractable ruler and the beam is positioned $100 \mathrm{~cm}$ from the cassette for the radiograph to be taken), we were unable to completely eliminate the possibilities of minor malrotation or magnification errors from using such a technique. We acknowledge that this is yet another limitation of the study. Despite this limitation, none of the radiographs in the study had to be excluded, as it is our institution's practice to repeat a radiograph if it is deemed unsatisfactory for surgical planning.

In conclusion, the present study found that there were statistically significant differences in the femoral head size and $\mathrm{CC}$ ratio among women of different ethnic groups. There were also differences in neck-shaft angles between Chinese and Indian women, and between Malay and Indian women. Although there were differences in the femoral head size and CC ratio among men of different ethnic groups, they were not statistically significant.

\section{REFERENCES}

1. Cooper C, Campion G, Melton LJ $3^{\text {rd }}$. Hip fractures in the elderly: a world-wide projection. Osteoporosis Int 1992; 2:285-9.

2. Leibson CL, Tosteson AN, Gabriel SE, Ransom JE, Melton LJ. Mortality, disability, and nursing home use for persons with and without hip fracture: a populationbased study. J Am Geriatr Soc 2002; 50:1644-50.
3. da Costa JA, Ribeiro A, Bogas M, et al. Mortality and functional impairment after hip fracture - a prospective study in a Portuguese population. Acta Reumatol Port 2009; 34:618-26.

4. Tan WL, Low SL, Shen L, Das De S. Osteoporotic hip fractures: 10-year review in a Singaporean hospital. J Orthop Surg (Hong Kong) 2015; 23:150-4.

5. Umer M, Sepah YJ, Khan A, et al. Morphology of the proximal femur in a Pakistani population. J Orthop Surg (Hong Kong) 2010; 18:279-81.

6. Lee CK, Kwan MK, Merican AM, et al. Femoral head diameter in the Malaysian population. Singapore Med J 2014; 55:436-8.

7. Chin PL, Tey TT, Ibrahim MY, et al. Intraoperative morphometric study of gender differences in Asian femurs. J Arthroplasty 2011; 26:984-8.

8. Dorr LD, Faugere MC, Mackel AM, et al. Structural and cellular assessment of bone quality of proximal femur. Bone 1993; 14:231-42.

9. Ministry of Health, Singapore Population and Vital Statistics. Available at: https:// www.moh.gov.sg/content/moh_web/home/statistics/Health_Facts_Singapore/ Population_And_Vital_Statistics.html. Accessed January 4, 2014.

10. Cooper HJ, Jacob AP, Rodriguez JA. Distal fixation of proximally coated tapered stems may predispose to a failure of osteointegration. J Arthroplasty 2011; 26(6 Suppl):78-83.

11. Ishii S, Homma Y, Baba T, et al. Does the canal fill ratio and femoral morphology of asian females influence early radiographic outcomes of total hip arthroplasty with an uncemented proximally coated, tapered-wedge stem? J Arthroplasty 2016; 31:1524-8.

12. Boymans TA, Heyligers IC, Grimm B. The Morphology of the Proximal Canal Continues to Change in the Very Elderly: Implications for Total Hip Arthroplasty. J Arthroplasty 2015; 30:2328-32.

13. Yeung Y, Chiu KY, Yau WP, et al. Assessment of the proximal femur morphology using plain radiograph-can it predict the bone quality? J Arthroplasty 2006; 21:508-13.

14. Ahlborg HG, Johnell O, Karlsson MK. An age-related medullary expansion can have implications for the long-term fixation of hip prostheses. Acta Orthop Scand 2004; 75:154-9.

15. Noble PC, Alexander JW, Lindahl LJ, et al. The anatomic basis of femoral component design. Clin Orthop Relat Res 1988; (235):148-65. 